Original articles and "fast-track short papers" are generally first-rate and span the field's multidisciplinary spectrum, including studies from comparative biology (cockroach, dolphin, marmot), neurology and the neurosciences, biological rhythms, psychopathology, methodology, endocrinology, regulatory physiology, gerontology, cognitive science and epidemiology. Although sleep-disorders medicine is not entirely eschewed, one feature that distinguishes $J S R$ from the other major journal devoted to sleep (the US periodical Sleep) is its more limited presentation of disease-oriented papers. Furthermore, such papers are more likely to focus on mechanism than treatment. $J S R$ has also published a consensus position paper (on sleep studies for sleepbreathing disorders) from the European sleep community. Such reports provide a valuable frame of reference for the global community of sleep clinicians. In summary, JSR is off to a superb start.

Mary A. Carskadon is in the Sleep Research Laboratory of E. P. Bradley Hospital, Brown University Medical School, 1011 Veterans Memorial Parkway, East Providence, Rhode Island 02915, USA.

\section{Aquatic outlets}

David R. Livingstone

Molecular Marine Biology and Biotechnology. Editor-in-chief Dennis Powers. Blackwell Scientific. 6/yr. USA $\$ 160$, Canada and Mexico $\$ 170$, elsewhere $\$ 190$ (institutional); USA $\$ 70$, Canada and Mexico $\$ 80$, elsewhere $\$ 100$ (personal).

Fish and Shellfish Immunology. Editors A. E. Ellis and M. F. Tatner. Academic. $7 / y r . £ 135, \$ 255$.

AQUATIC biologists will welcome the establishment of these two periodicals that gather together material previously scattered among the literature or tagged with the term 'comparative' and given a hard time by mainstream mammalianorientated journals. The editorial effort and standard of work evident in both will undoubtedly give a boost and some extra rigour to the fields covered.

Both journals are attractive and distinctive in appearance, and publish primary research papers, occasional reviews and short communications. Most of the work reported in the first volume of both $M M B B$ and $F S I$ is on fish (75 and 90 per cent respectively, including a special $M M B B$ double issue on transgenic fish), which may reflect research funding as much as anything else.

The launch of $M M B B$ is particularly timely. Molecular biological methods are being applied to more and more areas of science, yet until now there has been no obvious single publication outlet for aquatic scientists using such techniques. $M M B B$ aims to publish papers that apply these methods to biological and ecological questions. The editorial board is predominantly from the United States, but recruitment from other parts of the world is promised. The large format allows the inclusion of many photographs (such as western blots) and easily read and extensive gene sequences. Reproduction of detailed micrographs and colour photographs is excellent. Although most of the papers in the first issue are on DNA and RNA, a fair number also deal with protein or cell-biological studies, including enzyme purification and characterization. Papers of two to ten pages are requested. Although 'biotechnology' is in the journal's title and a stated aim is "to enhance the utilization of aquatic resources", it is to be hoped that applied matters do not come to overshadow the basic science.

FSI aims to present studies on the basic mechanisms of both the specific and nonspecific defence systems of fish and shellfish and the application of these findings to the aquaculture industry. It has a multinational editorial board, and to a limited extent overlaps with Disease of Aquatic Organisms, although the new journal's focus is exclusively on immunology. FSI will particularly help to galvanize and stimulate work on invertebrates.

David R. Livingstone is in the NERC Plymouth Marine Laboratory, Citadel Hall, Plymouth PL1 2PB, UK.

\section{In the incubator}

\section{John Blaxter}

Fisheries Oceanography. Editor-in-chief T. R. Parsons. Blackwell Scientific. 4/yr. USA and Canada \$157, Europe £95, elsewhere $£ 105$ (institutional); USA and Canada $\$ 89$, Europe $£ 55$, elsewhere $£ 60$ (personal).

THE birth of a journal follows a now familiar course: a distinguished scientist is appointed as editor (midwife) and is supported by a heavyweight editorial board of assistant midwives; the baby no doubt undergoes a gestation period of at least nine months but is underweight at birth and subsequently shows signs of uneven growth and imperfect development; all being well (that is, if libraries have adequate funding), a viable juvenile results. Fisheries Oceanography is no exception, and is presumably now in the incubator stage.

Publishers take well calculated risks in starting a new journal, knowing that perhaps $600-700$ institutional subscribers are needed for it to make a profit. The stated aim of Fisheries Oceanography is to publish original papers, reviews and short communications on research relating the production and dynamics of fish populations to the marine environment. The editor-in-chief is aided by two associate editors and an impressive editorial board of 21 scientists. In the four issues available for review, many of the papers can indeed be said to contain fisheries oceanography data but several cover purely fish biology and one purely oceanography. There is a fairly strong bias towards the North Pacific, reflecting, perhaps, the geographical location of two of the editors. Only one paper is on shellfish.

The standard of production is fair. The double-column format is not ideal for figures, many of which are too small and sometimes badly reproduced. Although the publishers have been parsimonious in this respect, they have allowed the publication of several colour plates, but it is not clear whether the authors have been charged for these. Colour can certainly be useful with the current vogue in satellite imagery and complex synoptic charts. At present, papers are accepted within two to three months of receipt and published within a few months. The editors are to be congratulated on getting their referees to report back within such a short time and the authors to revise their papers equally speedily.

Does this journal fulfil a need? A natural home for even a diffuse topic such as fisheries oceanography is useful, but there are many well established journals that are equally appropriate (for example, Canadian Journal of Fisheries and Aquatic Sciences, Fishery Bulletin US, ICES Journal of Marine Science and Marine Ecology, Progress Series). Fisheries oceanography is a long-standing topic. Why do not publishers confine themselves to commissioning journals in new fields?

Subscription prices are set at about the right rate - they will not deter librarians yet allow for some increase should the journal expand. In the surprising absence of an introductory editorial we are not party to the ambitions of the publishers and editors. Nor are we given the rationale for excluding lake fisheries and limnology, coverage of which would, in fact, have given the journal a wider and better remit. The danger is that librarians will wait to see how the baby progresses before taking a stake in its development. This means several years of subsidy by the publishers and some faith on the part of putative authors.

John Blaxter is at the Scottish Association for Marine Science, Dunstaffnage Marine Laboratory, PO Box 3, Oban, Argyll PA34 $4 A D, U K$. 